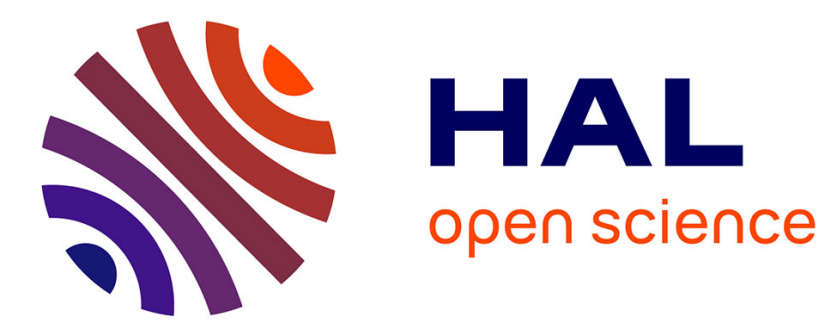

\title{
Interpreting pendred syndrome as a foetal hydrops: Clinical and animal model evidence
}

\author{
François Simon, Françoise Denoyelle, Mathieu Beraneck
}

\section{To cite this version:}

François Simon, Françoise Denoyelle, Mathieu Beraneck. Interpreting pendred syndrome as a foetal hydrops: Clinical and animal model evidence. Journal of Vestibular Research, 2021, 31 (4), pp.315321. 10.3233/ves-200789 . hal-03383212

\section{HAL Id: hal-03383212 https://hal.science/hal-03383212}

Submitted on 18 Oct 2021

HAL is a multi-disciplinary open access archive for the deposit and dissemination of scientific research documents, whether they are published or not. The documents may come from teaching and research institutions in France or abroad, or from public or private research centers.
L'archive ouverte pluridisciplinaire HAL, est destinée au dépôt et à la diffusion de documents scientifiques de niveau recherche, publiés ou non, émanant des établissements d'enseignement et de recherche français ou étrangers, des laboratoires publics ou privés. 


\title{
Interpreting pendred syndrome as a foetal hydrops: Clinical and animal model evidence
}

\author{
François Simon $^{\mathrm{a}, \mathrm{b}, \mathrm{c}, *}$, Françoise Denoyelle ${ }^{\mathrm{b}, \mathrm{c}}$ and Mathieu Beraneck ${ }^{\mathrm{a}}$ \\ ${ }^{a}$ Université de Paris, INCC UMR 8002, CNRS, F-75006 Paris, France \\ ${ }^{\mathrm{b}}$ Université de Paris, Faculté de Médecine, F-75006 Paris, France \\ ${ }^{\mathrm{c}}$ Department of Paediatric Otolaryngology, AP-HP, Hôpital Necker-Enfants Malades, F-75015 Paris, France
}

Received 30 January 2020

Accepted 15 January 2021

\begin{abstract}
.
BACKGROUND: Menière disease (MD) and SLC26A4 related deafness (Pendred syndrome (PS) or DFNB4) are two different inner ear disorders which present with fluctuating and progressive hearing loss, which could be a direct consequence of endolymphatic hydrops.

OBJECTIVE: To present similarities between both pathologies and explore how the concept of hydrops may be applied to PS/DFNB4.

METHODS: Review of the literature on MD, PS/DFNB4 and mouse model of PS/DFNB4.

RESULTS: MD and PS/DFNB4 share a number of similarities such as fluctuating and progressive hearing loss, acute episodes with vertigo and tinnitus, MRI and histological evidence of endolymphatic hydrops (although with different underlying mechanisms). MD is usually diagnosed during the fourth decade of life whereas PS/DFNB4 is congenital. The PS/DFNB4 mouse models have shown that biallelic slc26a4 mutations lead to $\mathrm{Na}^{+}$and water retention in the endolymph during the perinatal period, which in turn induces degeneration of the stria vascularis and hearing loss. Crossing clinical/imagery characteristics and animal models, evidence seems to support the hypothesis of PS being a foetal hydrops.

CONCLUSIONS: When understanding PS/DFNB4 as a developmental hydrops, treatments used in MD could be repositioned to PS.
\end{abstract}

Keywords: Menière, pendred, DFNB4, hydrops, mouse

\section{Introduction}

Menière's disease (MD) and endolymphatic hydrops are both very frequently discussed topics in the literature, although the underlying mechanisms are still poorly understood. First described in 1938 by Hallpike and Cairns [24], endolymphatic hydrops corresponds to a dilated endolymphatic sector within

${ }^{*}$ Corresponding author: François SIMON, Hôpital Necker Enfants Malades, AP-HP, 149 rue de Sèvres 75015 Paris, France. Tel.: +3368632 71 11; E-mail: fsimon05@gmail.com. the inner ear, and is considered as a histological basis for MD although it has also been found in other inner ear diseases. In addition, it is still debated whether endolymphatic hydrops is a cause or consequence of MD. Genetics seem to play a role in some sporadic and familial cases but are of a complex and polygenic nature [19].

SLC26A4 mutations are the cause of two autosomal recessive diseases, which share the same audiometric phenotype of progressive and fluctuating hearing loss (HL): Pendred syndrome (PS), a rare 
Table 1

Main differences and similarities between MD and PS/DFNB4

\begin{tabular}{ll}
\hline Differences & Similarities \\
\hline - Typical age of onset (MD in 40s; PS prelingual) & - Fluctuating and progressive HL \\
- Typical long-term HL severity (MD: moderate HL; PS: profound & - Acute HL episodes with vertigo and tinnitus \\
to severe) & - Enlarged endolymphatic space on MRI \\
- HL frequencies (MD: low-medium frequencies; PS: non-specific) & $\begin{array}{c}\text { - Histological evidence of endolymphatic hydrops (cadaveric } \\
\text { - CT-scan bony modifications (MD: normal; PS: EVA and Mondini) }\end{array}$ \\
\hline
\end{tabular}

EVA Enlarged vestibular aqueduct; $H L$ Hearing Loss; $M D$ Menière disease; $P S$ Pendred Syndrome.

syndrome deafness associated with thyroid disorders and DFNB4, an isolated deafness (SLC26A4 related deafness hereinafter referred to as PS/DFNB4). Recent studies on a mouse model of PS/DFNB4 have shown evidence of endolymphatic hydrops which could draw parallels with the better-known hydrops described in MD patients. Both MD and PS/DFNB4 correspond to internationally defined entities, yet may easily be confused with other types of fluctuating HL of idiopathic origin. Thus, for the sake of clarity, this paper will only discuss clinical presentations of definite MD (as defined by the American Academy of Otolaryngology-Head and Neck Surgery) and PS/DFNB4 with confirmed biallelic SLC26A4 mutations. The objective of this paper is to present similarities between both entities and explore how the concept of hydrops may be applied to PS/DFNB4.

\section{Menière versus Pendred, similarities and differences}

MD and PS/DFNB4 are two different inner ear disorders, which share a number of similarities and differences as reported in Table 1.

MD, first described by Prosper Menière in 1861, is the typical clinical example of hydrops. It has a very strict clinical definition, which was recently updated in 2015 [22]. Briefly, a patient must present with two or more spontaneous episodes of vertigo, ranging from 20 minutes to 12 hours long, with low to medium frequency sensorineural HL and aural symptoms (tinnitus or aural fullness), which cannot be accounted for by any other vestibular diagnosis. Symptoms which do not exactly correspond to this definition may be linked to endolymphatic hydrops and be considered as probable or possible MD. MD may have very different presentations from one patient to the other, but the key aspect is the fluctuating and progressive HL which spans out over several years. Over time, the HL worsens at all tested frequencies and becomes constant, usually stabilizing between 50 and
$70 \mathrm{~dB}$. Symptoms are usually unilateral, but up to half of patients present with bilateral symptoms, and the majority have bilateral electrophysiological or imagery anomalies (regardless of the contralateral ear being symptomatic or not) [27, 43]. This is an adult's disease, with most cases diagnosed in the fourth or fifth decade of life. Juvenile MD has been described in case reports in the literature, but remains extremely rare and linked to family history of MD [58]. The most frequent diagnosis in the child is vestibular migraine [61], but the clinical symptoms also resemble the rarer PS/DFNB4.

Vaughan Pendred first described Pendred syndrome in 1896, reporting an Irish family with congenital deafness and thyroid goitre. The disease has since then been linked to the SLC26A4 (or PDS) gene which codes for the pendrin protein $\left(\mathrm{Na}^{+}\right.$independent $\mathrm{Cl}^{-}$/Iodine/HCO3 ${ }^{-}$exchanger) [15]. Biallelic recessive mutation can cause DNFB4 isolated deafness or the Pendred syndrome when associated to a goitre (10-20\% of cases) and is estimated to be responsible for $5-15 \%$ of congenital HL $[1,2,17$, $37,42,56]$. The prevalence of SLC26A4 mutations is higher in China (carry rate $2.02 \%$ I la population of 2627 new-borns) [17]. Clinically, the same triad can be found as in MD, with episodes of fluctuating HL (although not specifically low to medium frequencies), vertigo and tinnitus. An auditory bonegap can be found in low frequencies, probably due to a third-window effect, but may as in some MD patients be due to decreased stapes mobility entailed by excessive endolymphatic pressure [51, $55,64]$. Symptoms vary from one patient to another, with unilateral or bilateral HL, and severity at birth ranging from cophosis to normal hearing. HL is however prelingual and progressive in the majority of cases (50-60\% and 70-90\% respectively) [42, 44, $46,56]$.

Concerning imagery, both vestibular disorders show signs of increased endolymphatic volume, although the aspect and mechanism are quite different. In MD, CT-scan is normal, MRI can show 


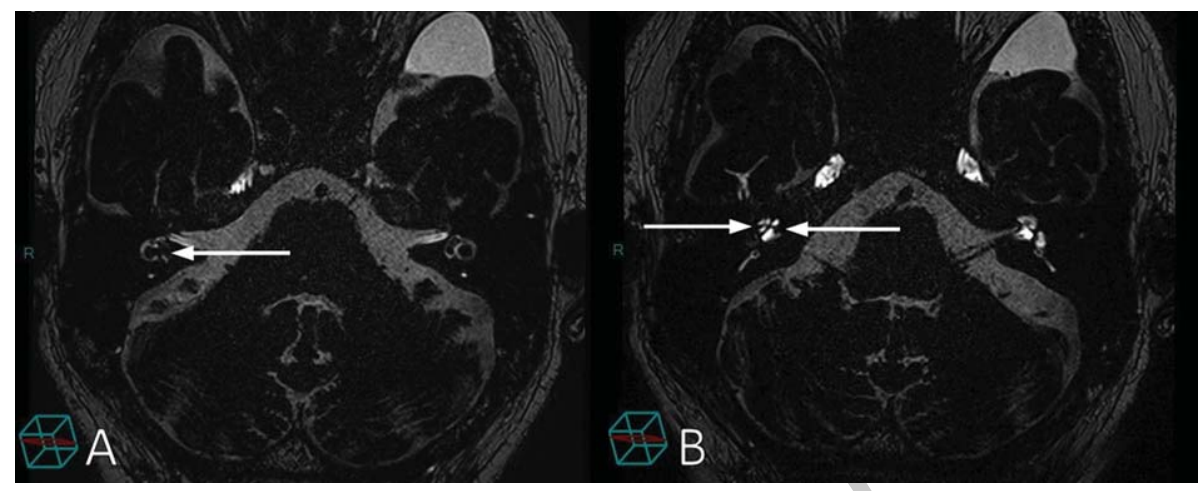

Fig. 1. MRI of hydrops in Menière disease. MRI 3D-FLAIR sequence $4 \mathrm{~h}$ after intravenous gadolinium injection. Imagery of a patient with right Menière disease. The MRI shows endolymphatic hydrops of vestibular and cochlear sectors in the right ear (and normal left ear). In the inner ear, the perilymph appears in hypersignal and endolymph in hyposignal. A: arrow shows utricular hydrops. B: left-to-right arrow shows cochlear hydrops; right-to-left arrow shows saccular hydrops. Curtesy from Michael Eliezer (Lariboisière Hospital, APHP, Paris, France).

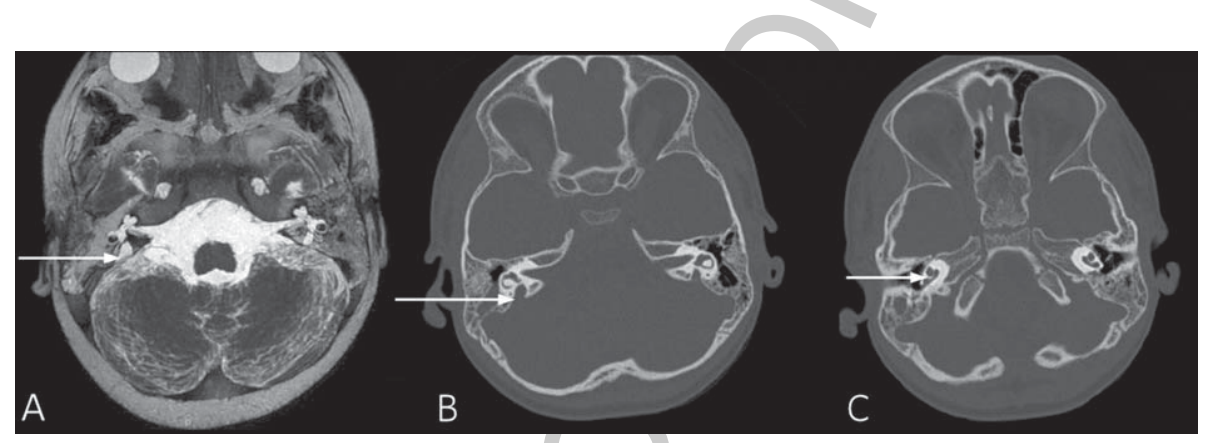

Fig. 2. CT-scan and MRI of hydrops in Pendred syndrome. Imagery of a patient with Pendred syndrome, with bilateral enlarged vestibular aqueduct (EVA), and cochlear incomplete partition type II (Mondini dysplasia). A: MRI T2 sequence, arrow shows the right EVA. B: CT-scan, arrow showing the right EVA with the large bony canal. C: CT-scan showing right Mondini dysplasia in the cochlea (only two turns).

endolymphatic hydrops concerning both cochlear and vestibular sectors (see Fig. 1), however saccular hydrops seems to be one of the most reproducible markers [3, 4, 39, 52, 57]. In PS/DFNB4, bilateral enlarged vestibular aqueduct (EVA), containing endolymph, is a constant feature in patients with biallelic mutations and may sometimes be associated with cochlear incomplete partition type II (Mondini dysplasia), as shown in Fig. 2. Both malformations can also be diagnosed on a CT-scan or MRI and are often indicators of PS/DFNB4 that usually precede genetic confirmation.

Vestibular function in MD is remarkable as there is, in most cases, a dissociation between caloric tests and vHIT $[13,25,50]$. This is probably due to the fact that while endolymphatic hydrops distorts the volume of the lateral semi-circular canal, thus inducing caloric hyporeflexia, the semi-circular canals still respond normally to high speed physiological stimulation. In the later stages of MD, the proportion of normal canal function (vHIT) and otolith function
(cVEMP and oVEMP) decrease [7, 13, 47]. Literature on the vestibular function in PS/DFNB4 is to date very poor due to its rarity, one study reporting canal paresis in $49 \%$ using caloric test [31]. Studies on EVA series (including PS/DFNB4 patients but not specific to SLC26A4 mutations) report abnormally low cVEMP (at 250 and $500 \mathrm{~Hz}$ ) thresholds and high amplitudes probably due to a third-window effect [62-64].

\section{Molecular genetics}

Although PS/DFNB4 is mainly linked to the biallelic SLC26A4 mutations, digenic mutations have been reported involving FOX11 or KCNJ10 genes [38]. Molecular genetics in MD, however, are less well understood. The rarer familial form (6 to $9 \%$ of MD cases) is a monogenic disorder and most families have an autosomal dominant inheritance with incomplete penetrance and variable expressivity $[41,54]$. 
Compound heterozygous mutations in $O T O G$ gene have been reported in several unrelated families with MD, suggesting a recessive inheritance pattern [48]. The majority of MD patients have a sporadic form, not clearly linked to any specific genetic disorders. Interestingly, sporadic MD does seem to be a polygenic condition and several sensorineural HL genes, including some hypomorphic alleles in SLC26A4, may contribute to the MD phenotype in sporadic cases [5, 20, 21].

\section{Animal models}

Lacking any unique genetic background or universally accepted histopathological hypothesis, it has been difficult to develop a specific animal model of MD [19]. A large number of models have been developed to try and mimic endolymphatic hydrops and fluctuating HL, usually requiring surgical endolymphatic sac destruction (to reduce endolymphatic resorption) or administration of medication to increase endolymphatic production (such as aldosterone) [12, 18, 26, 35]. These models rely on artificial disruption of the endolymphatic homeostasis. PS/DFNB4, on the other hand, has been clearly linked to a biallelic mutation of the SCL26A4 gene, and mouse models specific of this disease have been recently developed to understand underlying mechanisms.

It is first important to specify that in the mouse, development of the inner ear occurs throughout the perinatal period, starting at E9 (embryo day 9) with the otic placode and ending with a final adult structure at P20 (20 days after birth), whereas the human inner ear formation exclusively takes place during the foetal life ranging from 23 days to 8 months, respectively [23]. More precisely, key steps in mouse inner ear development are as follows: opening of endolymphatic sac lumen at E10.5; opening of cochlear lumen at E14.5; utricule and saccule are formed by E17; neuronal elements continue to develop during a period of differentiation and speciation from E17 to P7; mature endolymph produced at $\mathrm{P} 3$; endolymphatic potential matures from P7 to P15; with the onset of auditory function generally at P12; as well as the functional maturation of the vestibulo-ocular reflex which occurs after the opening of the eye at P12 [6, $23,59,60]$.

The first slc26a4 mouse biallelic knock-out model was developed in 1999 but showed a more severe phenotype than in humans, with congenital complete bilateral deafness and vestibular deficit behaviour. Pendrin expression was first detected at E13 in the duct and sac, and then at E15 in the utricule, saccule and cochlea. Enlarged endolymphatic space was demonstrated at E15 with secondary cochlea hair cell and macula destruction from P7 to P45 [14, 16, 49]. Further studies reported that pendrin in itself was not essential for hearing but defective pendrin caused HL via secondary mechanisms such as the degeneration, oxidative stress and macrophagic invasion of the stria vascularis $[30,49,60]$. Pendrin was demonstrated to be key in the endolymphatic homeostasis: lack of the $\mathrm{Cl}^{-} / \mathrm{HCO}^{-}$exchanger pendrin would decrease the endolymphatic $\mathrm{pH}$ as soon as E15.5 and thereby increase $\mathrm{Ca}^{2+}$ and $\mathrm{Na}^{+}$retention (by reducing the current that drives $\mathrm{Na}^{+}$reabsorption through $\mathrm{Na}^{+}$channels in the endolymphatic sac) $[32,33,36]$. Increased $\mathrm{Na}^{+}$endolymphatic concentration would in turn induce reduced endolymphatic potential and retain water creating endolymphatic hydrops. Finally, the mechanical effect of endolymphatic hydrops and increased cellular stress would entail cochlea stria vascularis degeneration around P10 (no data available for the vestibular system) [53, 59]. Other mice models have been developed with similar results, also showing a decreased amount of otoconia and giant or ectopic otoconia probably due to the altered endolymphatic calcium homeostasis [10, 11, 40]. Histological exploration and imagery of these mice models clearly showed endolymphatic hydrops.

Studies of the pendrin action timeframe were conducted on a dox-dependent mouse knock-out model, developed in 2011[8]. It was shown that absence of expression slc26a4 expression (no pendrin) before E16.5 or after P2 did not alter auditory brainstem responses (ABR) in these mice. However, absence of slc26a4 expression between E16.5 and E18.5 led to a decreased endolymphatic potential and $\mathrm{pH}$, although with normal ABR. Finally, absence of slc26a4 expression between E18.5 and P2 entailed a more severe state with abnormal ABR [8]. From these results, a model reproducing the human cochleavestibular phenotype of PS/DFNB4 was developed, with slc26a4 expression deactivated from E17.5 to $\mathrm{P} 2$, leading to fluctuating abnormal ABR and a progressive hearing loss at 6 months (vestibular function was not assessed) [28]. From this model, hypothesis was drawn that the pendrin expression in the endolymphatic sac would be necessary in the mouse to allow acquisition of normal hearing in the perinatal period $[29,45]$. 


\section{A foetal hydrops}

PS/DFNB4 in the mouse model seems to be secondary to modification of endolymphatic fluid absorption in the developing inner ear. Although the exact molecular mechanisms may differ in human PS/DFNB4, the process is probably comparable. The timing of these events in the human inner ear is unknown, but by comparing the timetable of mouse and human ear development, we may suppose they could take place during the human foetal and early postnatal life, with the most sensitive moment (corresponding to the mouse perinatal period) taking place in a 3 to 4-month-old foetus, well before birth [23]. Although gene therapy seems promising $[9,34]$, this timing causes great difficulties, first in terms of diagnostic opportunities, and then of treatment strategies.

Crossing results from the animal model with children's imagery, we could hypothesise that foetal endolymphatic hydrops, may induce inner ear bulging before cranial ossification occurs, thus rendering the cochleo-vestibular malformations visible on the CTscan at birth. This foetal hydrops may be already advanced at birth, with congenital bilateral cophosis, in which case management would have to rely (as it does today) on auditory rehabilitation such as cochlear implant. In the cases where congenital hydrops is associated with residual to normal hearing, specific treatment, yet to be developed, may become key: on one hand, gene therapy or inner ear medication (research on animal models) and on the other hand, repositioning of established hydrops treatment (currently used in MD) to treat fluctuating episodes.

\section{Conclusion}

- MD and PS/DFNB4 are two different inner ear disorders linked to endolymphatic hydrops.

- MD is more common and its literature abundant whereas PS/DFNB4 remains poorly described, especially its vestibular characteristics.

- The main common feature is fluctuating and progressive HL.

- PS/DFNB4 mouse models have helped identify the role of pendrin and how biallelic slc26a4 mutation lead to $\mathrm{Na}^{+}$and water retention in the endolymph.

- Parallels may be drawn between mechanisms highlighted in the mouse PS/DFNB4 model and physiopathological hypothesis in MD.
- Mutations in sensorineural HL genes, including SLC26A4, may contribute to MD phenotype.

- PS/DFNB4 could be understood as a developmental hydrops and thus, benefit from MD knowledge and therapies

\section{Conflict of interest statement}

The authors do not have any commercial or other association that might pose a conflict of interest. The authors did not have any financial support to write this paper.

\section{References}

[1] C. Aimoni, A. Ciorba, L. Cerritelli, S. Ceruti, P.H. Skarzynski and S. Hatzopoulos, Enlarged vestibular aqueduct: Audiological and genetical features in children and adolescents, Int J Pediatr Otorhinolaryngol 101 (2017), 254-258.

[2] S. Albert, H. Blons, L. Jonard, D. Feldmann, P. Chauvin, N. Loundon, A. Sergent-Allaoui, M. Houang, A. Joannard, S. Schmerber, B. Delobel, J. Leman, H. Journel, H. Catros, H. Dollfus, M.M. Eliot, A. David, C. Calais, V. DrouinGarraud, M.F. Obstoy, P. Tran Ba Huy, D. Lacombe, F. Duriez, C. Francannet, P. Bitoun, C. Petit, E.N. Garabedian, R. Couderc, S. Marlin and F. Denoyelle, SLC26A4 gene is frequently involved in nonsyndromic hearing impairment with enlarged vestibular aqueduct in Caucasian populations, Eur J Hum Genet EJHG 14 (2006), 773-779.

[3] A. Attyé, M. Eliezer, N. Boudiaf, I. Tropres, D. Chechin, S. Schmerber, G. Dumas and A. Krainik, MRI of endolymphatic hydrops in patients with Meniere's disease: A case-controlled study with a simplified classification based on saccular morphology, Eur Radiol 27 (2017), 3138-3146.

[4] A. Attyé, M. Eliezer, M. Medici, I. Tropres, G. Dumas, A. Krainik and S. Schmerber, In vivo imaging of saccular hydrops in humans reflects sensorineural hearing loss rather than Meniere's disease symptoms, Eur Radiol 28 (2018), 2916-2922.

[5] H. Azaiez, K.T. Booth, S.S. Ephraim, B. Crone, E.A. BlackZiegelbein, R.J. Marini, A.E. Shearer, C.M. Sloan-Heggen, D. Kolbe, T. Casavant, M.J. Schnieders, C. Nishimura, T. Braun and R.J.H. Smith, Genomic Landscape and Mutational Signatures of Deafness-Associated Genes, Am J Hum Genet 103 (2018), 484-497.

[6] M. Beraneck, F.M. Lambert and S.G. Sadeghi, Functional development of the vestibular system: Sensorimotor pathways for stabilization of gaze and posture. In: Development of auditory and vestibular systems. Elsevier, pp 449-487.

[7] L. Chen, H. Xu, W. Wang, Q. Zhang, Q. Lv and X. Song, Evaluation of the otolith function using c/oVEMPs in patients with Ménière's disease, J Otolaryngol-Head Neck Surg 45 (2016), 39.

[8] B.Y.Choi, H.M. Kim, T. Ito, K.Y. Lee, X. Li, K. Monahan, Y. Wen, E. Wilson, K. Kurima, T.L. Saunders, R.S. Petralia, P. Wangemann, T.B. Friedman and A.J. Griffith, Mouse model of enlarged vestibular aqueducts defines temporal requirement of Slc26a4 expression for hearing acquisition, J Clin Invest 121 (2011), 4516-4525. 
[9] H.J. Choi, H.J. Lee, J.Y. Choi, I.H. Jeon, B. Noh, S. Devkota, H.-W. Lee, S.K. Eo, J.Y. Choi and M.G. Lee, DNAJC14 ameliorates inner ear degeneration in the DFNB4 mouse model, Mol Ther-Methods Clin Dev 17 (2020), 188-197.

[10] A.A. Dror and K.B. Avraham, The Slc26a4 loop Mouse Model for Pendred's Syndrome and Nonsyndromic Deafness. In: The Role of Pendrin in Health and Disease. Springer, pp. 23-36.

[11] A.A. Dror, Y. Politi, H. Shahin, D.R. Lenz, S. Dossena, C. Nofziger, H. Fuchs, M. Hrabe de Angelis, M. Paulmichl, S. Weiner and K.B. Avraham, Calcium oxalate stone formation in the inner ear as a result of an Slc26a4 mutation, $J$ Biol Chem 285 (2010), 21724-21735.

[12] E. Dunnebier, J. Segenhout, H. Wit and F. Albers, Twophase endolymphatic hydrops: a new dynamic guinea pig model, Acta Otolaryngol (Stockh) 117 (1997), 13-19.

[13] B.F. van Esch, K. Abolhosseini, S. Masius-Olthof, H.J. van der Zaag-Loonen, P.P.G. van Benthem and T.D. Bruintjes, Video-head impulse test results in patients with Menière's disease related to duration and stage of disease, $J$ Vestib Res Equilib Orientat 28 (2018), 401-407.

[14] L.A. Everett, I.A. Belyantseva, K. Noben-Trauth, R. Cantos, A. Chen, S.I. Thakkar, S.L. Hoogstraten-Miller, B. Kachar, D.K. Wu and E.D. Green, Targeted disruption of mouse Pds provides insight about the inner-ear defects encountered in Pendred syndrome, Hum Mol Genet 10 (2001), 153-61.

[15] L.A. Everett, B. Glaser, J.C. Beck, J.R. Idol, A. Buchs, M. Heyman, F. Adawi, E. Hazani, E. Nassir, A.D. Baxevanis, V.C. Sheffield and E.D. Green, Pendred syndrome is caused by mutations in a putative sulphate transporter gene (PDS), Nat Genet 17 (1997), 411-422.

[16] L.A. Everett, H. Morsli, D.K. Wu and E.D. Green, Expression pattern of the mouse ortholog of the Pendred's syndrome gene (Pds) suggests a key role for pendrin in the inner ear, Proc Natl Acad Sci U A 96 (1999), 9727-932.

[17] Y. Fang, M. Gu, C. Wang, F. Suo, G. Wang and Y. Xia, GJB2 as Well as SLC26A4 Gene Mutations are Prominent Causes for Congenital Deafness, Cell Biochem Biophys 73 (2015), 41-44.

[18] E. Ferrary and O. Sterkers, Mechanisms of endolymph secretion, Kidney Int Suppl 65 (1998), S98-103.

[19] A. Gallego-Martinez and J.A. Lopez-Escamez, Genetic architecture of Meniere's disease, Hear Res (2019), 107872.

[20] A. Gallego-Martinez, T. Requena, P. Roman-Naranjo and J.A. Lopez-Escamez, Excess of Rare Missense Variants in Hearing Loss Genes in Sporadic Meniere Disease, Front Genet 10 (2019), 76.

[21] A. Gallego-Martinez, T. Requena, P. Roman-Naranjo, P. May and J.A. Lopez-Escamez, Enrichment of damaging missense variants in genes related with axonal guidance signalling in sporadic Meniere's disease, J Med Genet 57 (2020), 82-88.

[22] J.A. Goebel, 2015 Equilibrium Committee Amendment to the 1995 AAO-HNS Guidelines for the Definition of Ménière's Disease, Otolaryngol-Head Neck Surg Off J Am Acad Otolaryngol-Head Neck Surg 154 (2016), 403-404.

[23] R.J. Gorlin, H.V. Toriello and M.M. Cohen, Hereditary hearing loss and its syndromes. Oxford University Press, USA.

[24] C.S. Hallpike and H. Cairns, Observations on the pathology of Meniere's syndrome, J Laryngol Otol $\mathbf{5 3}$ (1938), 625-655.

[25] I.P. Hannigan, M.S. Welgampola, and S.R.D. Watson, Dissociation of caloric and head impulse tests: a marker of Meniere's disease, J Neurol. doi: 10.1007/s00415-01909431-9
[26] K.C. Horner, Auditory and vestibular function in experimental hydrops, Otolaryngol Neck Surg 112 (1995), 84-89.

[27] C.-H. Huang and Y.-H. Young, Bilateral Meniere's disease assessed by an inner ear test battery, Acta Otolaryngol (Stockh) 135 (2015), 233-238.

[28] T. Ito, X. Li, K. Kurima, B.Y. Choi, P. Wangemann and A.J. Griffith, Slc26a4-insufficiency causes fluctuating hearing loss and stria vascularis dysfunction, Neurobiol Dis $\mathbf{6 6}$ (2014), 53-65.

[29] T. Ito, A. Nishio, P. Wangemann and A.J. Griffith, Progressive irreversible hearing loss is caused by stria vascularis degeneration in an Slc26a4-insufficient mouse model of large vestibular aqueduct syndrome, Neuroscience $\mathbf{3 1 0}$ (2015), 188-197.

[30] S.V. Jabba, A. Oelke, R. Singh, R.J. Maganti, S. Fleming, S.M. Wall, L.A. Everett, E.D. Green and P. Wangemann, Macrophage invasion contributes to degeneration of stria vascularis in Pendred syndrome mouse model, BMC Med $\mathbf{4}$ (2006), 37.

[31] J. Jung, Y.W. Seo, J.Y. Choi and S.H. Kim, Vestibular function is associated with residual low-frequency hearing loss in patients with bi-allelic mutations in the SLC26A4 gene, Hear Res 335 (2016), 33-39.

[32] H.M. Kim and P. Wangemann, Failure of fluid absorption in the endolymphatic sac initiates cochlear enlargement that leads to deafness in mice lacking pendrin expression, PLoS One 5 (2010), e14041.

[33] H.M. Kim and P. Wangemann, Epithelial cell stretching and luminal acidification lead to a retarded development of stria vascularis and deafness in mice lacking pendrin, PLoS One 6 (2011), e17949.

[34] M.-A. Kim, S.H. Kim, N. Ryu, J.-H. Ma, Y.-R. Kim, J. Jung, C.-J. Hsu, J.Y. Choi, K.-Y. Lee and P. Wangemann, Gene therapy for hereditary hearing loss by SLC26A4 mutations in mice reveals distinct functional roles of pendrin in normal hearing, Theranostics 9 (2019), 7184.

[35] R. Kimura and H. Schuknecht, Membranous hydrops in the inner ear of the guinea pig after obliteration of the endolymphatic sac, Orl 27 (1965), 343-354.

[36] X. Li, J.D. Sanneman, D.G. Harbidge, F. Zhou, T. Ito, R. Nelson, N. Picard, R. Chambrey, D. Eladari, T. Miesner, A.J. Griffith, D.C. Marcus and P. Wangemann, SLC26A4 targeted to the endolymphatic sac rescues hearing and balance in Slc26a4 mutant mice, PLoS Genet 9 (2013), e1003641.

[37] X.C. Li, L.A. Everett, A.K. Lalwani, D. Desmukh, T.B. Friedman, E.D. Green and E.R. Wilcox, A mutation in PDS causes non-syndromic recessive deafness, Nat Genet $\mathbf{1 8}$ (1998), 215-217.

[38] Y.-H. Lin, C.-C. Wu, Y.-H. Lin, Y.-C. Lu, C.-S. Chen, T.-C. Liu, P.-L. Chen and C.-J. Hsu, Targeted Next-Generation Sequencing Facilitates Genetic Diagnosis and Provides Novel Pathogenetic Insights into Deafness with Enlarged Vestibular Aqueduct, J Mol Diagn JMD 21 (2019), 138-148.

[39] J.A. Lopez-Escamez and A. Attyé, Systematic review of magnetic resonance imaging for diagnosis of Meniere disease, J Vestib Res Equilib Orientat 29 (2019), 121-129.

[40] Y.C. Lu, C.C. Wu, W.S. Shen, T.H. Yang, T.H. Yeh, P.J. Chen, I.S. Yu, S.W. Lin, J.M. Wong, Q. Chang, X. Lin and C.J. Hsu, Establishment of a knock-in mouse model with the SLC26A4 c. $919-2 \mathrm{~A}>\mathrm{G}$ mutation and characterization of its pathology, PLoS One 6 (2011), e22150.

[41] C. Martín-Sierra, A. Gallego-Martinez, T. Requena, L. Frejo, A. Batuecas-Caletrío and J.A. Lopez-Escamez, Variable expressivity and genetic heterogeneity involving DPT and SEMA3D genes in autosomal dominant famil- 
ial Meniere's disease, Eur J Hum Genet EJHG 25 (2017), 200-207.

[42] M. Miyagawa, S.Y. Nishio and S. Usami, Mutation spectrum and genotype-phenotype correlation of hearing loss patients caused by SLC26A4 mutations in the Japanese: a large cohort study, J Hum Genet 59 (2014), 262-268.

[43] K. Morimoto, T. Yoshida, S. Sugiura, M. Kato, K. Kato, M. Teranishi, S. Naganawa, T. Nakashima and M. Sone, Endolymphatic hydrops in patients with unilateral and bilateral Meniere's disease, Acta Otolaryngol (Stockh) 137 (2017), 23-28.

[44] J.W. van Nierop, W.J. Huinck, R.J. Pennings, R.J. Admiraal, E.A. Mylanus and H.P. Kunst, Patients with Pendred syndrome: is cochlear implantation beneficial? Clin Otolaryngol 41 (2016), 386-394.

[45] A. Nishio, T. Ito, H. Cheng, T.S. Fitzgerald, P. Wangemann and A.J. Griffith, Slc26a4 expression prevents fluctuation of hearing in a mouse model of large vestibular aqueduct syndrome, Neuroscience 329 (2016), 74-82.

[46] Y. Okamoto, H. Mutai, A. Nakano, Y. Arimoto, T. Sugiuchi, S. Masuda, N. Morimoto, H. Sakamoto, N. Ogahara, A. Takagi, H. Taiji, K. Kaga, K. Ogawa and T. Matsunaga, Subgroups of enlarged vestibular aqueduct in relation to SLC26A4 mutations and hearing loss, Laryngoscope 124 (2014), E134-40.

[47] T. Okumura, T. Imai, Y. Takimoto, N. Takeda, T. Kitahara, A. Uno, T. Kamakura, Y. Osaki, Y. Watanabe and H. Inohara, Assessment of endolymphatic hydrops and otolith function in patients with Meniere's disease, Eur Arch Otorhinolaryngol 274 (2017), 1413-1421.

[48] P. Roman-Naranjo, A. Gallego-Martinez, A. Soto-Varela, I. Aran, M.D.C. Moleon, J.M. Espinosa-Sanchez, J.C. AmorDorado, A. Batuecas-Caletrio, P. Perez-Vazquez and J.A. Lopez-Escamez, Burden of Rare Variants in the OTOG Gene in Familial Meniere's Disease, Ear Hear 41 (2020), 1598-1605.

[49] I.E. Royaux, I.A. Belyantseva, T. Wu, B. Kachar, L.A. Everett, D.C. Marcus and E.D. Green, Localization and functional studies of pendrin in the mouse inner ear provide insight about the etiology of deafness in pendred syndrome, J Assoc Res Otolaryngol 4 (2003), 394-404.

[50] F. Rubin, F. Simon, B. Verillaud, P. Herman, R. Kania and C. Hautefort, Comparison of Video Head Impulse Test and Caloric Reflex Test in advanced unilateral definite Menière's disease, Eur Ann Otorhinolaryngol Head Neck Dis 135 (2018), 167-169.

[51] Y.J. Seo, J. Kim and J.Y. Choi, Correlation of vestibular aqueduct size with air-bone gap in enlarged vestibular aqueduct syndrome, Laryngoscope 126 (2016), 1633-1638.

[52] F. Simon, J.P. Guichard, R. Kania, J. Franc, P. Herman and C. Hautefort, Saccular measurements in routine MRI can predict hydrops in Meniere's disease, Eur Arch Oto-RhinoLaryngol Off J Eur Fed Oto-Rhino-Laryngol Soc EUFOS
Affil Ger Soc Oto-Rhino-Laryngol - Head Neck Surg 274 (2017), 4113-4120.

[53] R. Singh and P. Wangemann, Free radical stress-mediated loss of Kcnj10 protein expression in stria vascularis contributes to deafness in Pendred syndrome mouse model, $\mathrm{Am}$ J Physiol Ren Physiol 294 (2008), F139-48.

[54] S. Skarp, L. Kanervo, J. Kotimäki, M. Sorri, M. Männikkö and E. Hietikko, Whole-exome sequencing suggests multiallelic inheritance for childhood-onset Ménière's disease, Ann Hum Genet. doi: 10.1111/ahg.12327

[55] S. Sugimoto, T. Yoshida, M. Teranishi, Y. Okazaki, S. Naganawa and M. Sone, The relationship between endolymphatic hydrops in the vestibule and low-frequency air-bone gaps, The Laryngoscope 128 (2018), 1658-1662.

[56] H. Suzuki, A. Oshima, K. Tsukamoto, S. Abe, K. Kumakawa, K. Nagai, H. Satoh, Y. Kanda, S. Iwasaki and S. Usami, Clinical characteristics and genotype-phenotype correlation of hearing loss patients with SLC26A4 mutations, Acta Otolaryngol 127 (2007), 1292-1297.

[57] A. Venkatasamy, F. Veillon, A. Fleury, M. Eliezer, M. Abu Eid, B. Romain, H. Vuong, D. Rohmer, A. Charpiot, H. Sick and S. Riehm, Imaging of the saccule for the diagnosis of endolymphatic hydrops in Meniere disease, using a three-dimensional T2-weighted steady state free precession sequence: accurate, fast, and without contrast material intravenous injection, Eur Radiol Exp 1 (2017), 14.

[58] C. Wang, C.-H. Wu, P.-W. Cheng and Y.-H. Young, Pediatric Meniere's disease, Int J Pediatr Otorhinolaryngol 105 (2018), 16-19.

[59] P. Wangemann, The role of pendrin in the development of the murine inner ear, Cell Physiol Biochem 28 (2011), 527-34.

[60] P. Wangemann, E.M. Itza, B. Albrecht, T. Wu, S.V. Jabba, R.J. Maganti, J.H. Lee, L.A. Everett, S.M. Wall, I.E. Royaux, E.D. Green and D.C. Marcus, Loss of KCNJ10 protein expression abolishes endocochlear potential and causes deafness in Pendred syndrome mouse model, BMC Med 2 (2004), 30.

[61] S.R. Wiener-Vacher, J. Quarez and A.L. Priol, Epidemiology of Vestibular Impairments in a Pediatric Population, Semin Hear 39 (2018), 229-242.

[62] C.J. Yang, V. Lavender, J.K. Meinzen-Derr, A.P. Cohen, M. Youssif, M. Castiglione, V. Manickam, K.R. Bachmann and J.H. Greinwald, Vestibular pathology in children with enlarged vestibular aqueduct, Laryngoscope 126 (2016), 2344-2350.

[63] C.K. Zalewski, W.W. Chien, K.A. King, J.A. Muskett, R.E. Baron, J.A. Butman, A.J. Griffith and C.C. Brewer, Vestibular Dysfunction in Patients with Enlarged Vestibular Aqueduct, Otolaryngol Head Neck Surg 153 (2015), 257-262.

[64] G. Zhou and Q. Gopen, Characteristics of vestibular evoked myogenic potentials in children with enlarged vestibular aqueduct, Laryngoscope 121 (2011), 220-225. 